\title{
Towards implementing exercise into the prostate cancer care pathway: development of a theory and evidence- based intervention to train community- based exercise professionals to support change in patient exercise behaviour (The STAMINA trial)
}

Sophie Reale ${ }^{1}$, Rebecca R. Turner ${ }^{1}$, Eileen Sutton², Stephanie J. C. Taylor ${ }^{3}$, Liam Bourke ${ }^{1}$, Dylan Morrissey ${ }^{4}$, Janet Brown ${ }^{5}$, Derek J. Rosario ${ }^{1,6}$ and Liz Steed ${ }^{3^{*}}$

\begin{abstract}
Background: The National Institute for Health and Care Excellence (NICE) recommend that men on androgen deprivation therapy (ADT) for prostate cancer should receive supervised exercise to manage the side-effects of treatment. However, these recommendations are rarely implemented into practice. Community-based exercise professionals (CBEPs) represent an important target group to deliver the recommendations nationally, yet their standard training does not address the core competencies required to work with clinical populations, highlighting a need for further professional training. This paper describes the development of a training package to support CBEPs to deliver NICE recommendations.

Methods: Development of the intervention was guided by the Medical Research Council guidance for complex interventions and the Behaviour Change Wheel. In step one, target behaviours, together with their barriers and facilitators were identified from a literature review and focus groups with CBEPs $(n=22)$ and men on androgen deprivation therapy ( $n=26$ ). Focus group outputs were mapped onto the Theoretical Domains Framework (TDF) to identify theoretical constructs for change. In step two, behaviour change techniques and their mode of delivery were selected based on psychological theories and evidence to inform intervention content. In step three, the intervention was refined following delivery and subsequent feedback from intervention recipients and stakeholders. (Continued on next page)
\end{abstract}

\footnotetext{
* Correspondence: e.a.steed@gmul.ac.uk

${ }^{3}$ Institute for Population Health Sciences, Queen Mary University of London, London, UK

Full list of author information is available at the end of the article
}

C C The Author(s). 2021 Open Access This article is licensed under a Creative Commons Attribution 4.0 International License, which permits use, sharing, adaptation, distribution and reproduction in any medium or format, as long as you give appropriate credit to the original author(s) and the source, provide a link to the Creative Commons licence, and indicate if changes were made. The images or other third party material in this article are included in the article's Creative Commons licence, unless indicated otherwise in a credit line to the material. If material is not included in the article's Creative Commons licence and your intended use is not permitted by statutory regulation or exceeds the permitted use, you will need to obtain permission directly from the copyright holder. To view a copy of this licence, visit http://creativecommons.org/licenses/by/4.0/. The Creative Commons Public Domain Dedication waiver (http://creativecommons.org/publicdomain/zero/1.0/) applies to the data made available in this article, unless otherwise stated in a credit line to the data. 
(Continued from previous page)

Results: Six modifiable CBEPs target behaviours were identified to support the delivery of the NICE recommendations. Nine domains of the TDF were identified as key determinants of change, including: improving knowledge and skills and changing beliefs about consequences. To target the domains, we included 20 BCTs across 8 training modules and took a blended learning approach to accommodate different learning styles and preferences. Following test delivery to 11 CBEPs and feedback from 28 stakeholders, the training package was refined.

Conclusion: Established intervention development approaches provided a structured and transparent guide to intervention development. A training package for CBEPs was developed and should increase trust amongst patients and health care professionals when implementing exercise into prostate cancer care. Furthermore, if proven effective, the development and approach taken may provide a blueprint for replication in other clinical populations where exercise has proven efficacy but is insufficiently implemented.

Keywords: Prostate cancer, Androgen deprivation therapy, Exercise, Exercise professionals, Behaviour change, Intervention development, Behaviour change wheel, Person based approach, Medical Research Council, Patient and public involvement

\section{Background}

Prostate cancer is common worldwide, totalling approximately 1.3 million new cases in men in 2018 [1]. More specifically, prostate cancer is the most common cancer diagnosis in men in the UK, with 41,201 new cases in 2017 [2]. Approximately half of men diagnosed with prostate cancer will undergo androgen deprivation therapy (ADT), also known as medical castration [3]. This is an ongoing treatment administered via injection, tablet or surgery. Whilst ADT is effective in treating prostate cancer, persistent adverse effects are common and can be debilitating thus impacting on overall quality of life (QoL) (e.g. fatigue, reduced muscle mass, loss of bone mineral density, hot flushes, and sexual dysfunction) [4].

Numerous strategies to manage the side effects of ADT have been described and tested in practise [5]. However, to date the only evidence-based treatment to demonstrate clinically meaningful improvements to fatigue and disease specific QoL, are non-pharmacological interventions, predominantly exercise training [6, 7]. As such, the National Institute for Health and Care Excellence (NICE; NG131 1.4.19) include in the guidelines for locally advanced and advanced prostate cancer a recommendation that men on ADT should be offered supervised, aerobic and resistance exercise twice weekly for 12 weeks [8]. However, these recommendations are seldom integrated into practise [9] due to several reported barriers from healthcare professionals (HCPs), including a lack of exercise services to refer men to [10] and limited awareness of clinical exercise recommendations [11], thus adding to unmet needs reported by men with prostate cancer [12]. Furthermore, men on ADT who participated in a 12-month supervised exercise programme believe community gyms are easily accessible and a location they look forward to attending [13].
A genuine opportunity exists to improve the QoL of men with prostate cancer on ADT, with exercise professionals supporting the delivery of recommendations nationally (i.e. NG131 1.4.19). More specifically, findings from our earlier work, including interviews with a diverse range of healthcare professionals working in the NHS prostate cancer care and exercise referral pathway highlight that HCPs and allied health professionals, (including physiotherapists), do not perceive delivering NICE recommendations (i.e. NG131 1.4.19) as part of their role [9]. Instead, community-based exercise professionals (CBEPs) (i.e., physiologists, physiotherapists and personal trainers based within the leisure industry) are deemed more suitable. For example, the role of CBEPs is to design and deliver safe and effective exercise programmes. Their success in this role has been demonstrated in previous exercise trials e.g. [14] and is in line with regulation by the Chartered Institute for the Management of Sport and Physical Activity (CIMSPA) [15]. Therefore, we intend a service level change in the prostate cancer care pathway by integrating two currently distinct sectors (the leisure industry and the NHS). We aim to explore the implementation of NICE recommendations into practice, as part of an ongoing research project; STAMINA (Supported exercise TrAining for Men wIth prostate caNcer on Androgen deprivation therapy).

However, integration of these two sectors is not without challenge. Interviews with HCPs in the prostate cancer care pathway have highlighted concerns regarding patient safety when exercising in the community due to a lack of confidence in CBEP's skills to deliver a safe, and disease specific, exercise programme [9]. Similarly, men on ADT emphasise the need for exercise to be supervised by a professional and tailored to meet their individual needs [9]. These beliefs are possibly reflective of limited HCP and patient knowledge of the training 
CBEPs receive, the typically short duration and/ or limited regulation for personal training qualification [16]; the variation in CBEPs behaviour change and communication skills, and limited CBEPs knowledge related to prostate cancer. Evidence suggests standard exercise professional qualifications do not address the core competencies of working with clinical populations highlighting a need for further appropriate professional training to ensure safety [16].

This paper describes the methods used and outcomes realised from the development and refinement of a theory and evidence-based intervention (as part of the STAMINA programme) to facilitate CBEPs to support men on ADT for prostate cancer to initiate, and further maintain, exercise behaviour. The structure was guided by formalised intervention development approaches: the UK Medical Research Council (MRC) guidance for the development and evaluation of complex interventions, emphasising the importance of drawing on evidence and theory and specifying key steps in the intervention development process [17], and the Behaviour Change Wheel (BCW) [18] complemented by elements of the PersonBased Approach [19], as has been used previously [20]. The BCW is a guide to intervention development informed by theory and based on the synthesis of 19 behaviour change frameworks [18]. The Person-Based Approach complements the $\mathrm{BCW}$ by focussing primarily on users' perspective and the context of an intervention to enhance acceptability and the likely engagement with, and effectiveness of, an intervention [19].

The aim of this research was to develop a theory and evidence-based training package for CBEPs to support the delivery of the NICE recommendations NG131 1.4.19, prior to full effectiveness and implementation evaluation in a planned randomised controlled trial. In parallel, training for HCPs to provide exercise recommendation and support was developed after further professional training requirements were identified as part of the STAMINA programme (methods reported elsewhere; under review).

\section{Methods}

The intervention was developed in accordance with the MRC guidance for the development of complex interventions $[17,21]$ and took a theory and evidence based approach. The BCW [18] in conjunction with elements of the Person-Based Approach [19] provided a systematic guide to intervention development, incorporating user perspectives, with the aim of changing CBEPs behaviour. The intervention was refined through an iterative and dynamic process based on evidence, theory and feedback from intervention recipients, patient and public involvement (PPI) members, stakeholders and an expert working group with expertise in: behaviour change (SR,
LS, RT), complex intervention development (ST), cancer research (LB, DR), urology (DR) and qualitative methodologies (ES) (Fig. 1).

Regulatory and ethical approvals, in accordance with the Helsinki Declaration, were sought prior to the commencement of research activities from Sheffield Hallam University (Reference: ER10748795) and the NHS (REC reference: 18/NW/0738 / IRAS project ID: 254343). Written informed consent was collected from all participations prior to research activity.

\section{Step one: understanding the behaviour}

To develop a complex intervention centred on supporting patient behaviour, we firstly sought to understand patient needs i.e. what support do men on ADT for prostate cancer need to exercise. We then identified how to train CBEPs to deliver the required support to men on ADT, as detailed below.

\section{Identification and selection of target behaviours}

A list of potential target behaviours for patients and CBEPs were generated by reviewing i) existing literature examining the effectiveness of interventions aimed at exercise initiation and maintenance of cancer survivors and the role of exercise professionals [22] and ii) results of 5 focus groups with men on ADT for prostate cancer $(n=26)$, exploring their experiences of physical activity and beliefs about participating in a structured exercise programme (methods reported elsewhere [9]).

The comprehensive list of behaviours was reviewed by the expert working group for replication or cross-over between behaviours. Each behaviour was then coded according to defined criteria from the BCW [18], to identify behaviours that should be targeted in the intervention: a) the likely impact of change, b) the likely ease of change, c) the centrality of the behaviour (e.g. the likelihood of changing one behaviour having an impact on another behaviour) and d) the ease of measurement. Coding was completed by an individual researcher (SR) and verified through discussion with the expert working group including review by a behaviour change expert (LS).

\section{Specification of target behaviours}

Next, the target behaviours were specified in behavioural terms by the expert working group, and reviewed by the PPI group (7 men with prostate cancer and 4 family members); who needs to deliver the behaviour, what does a person need to do differently, when will it happen and where will it take place. To consider dose we also considered how often the behaviours are required and with whom. 


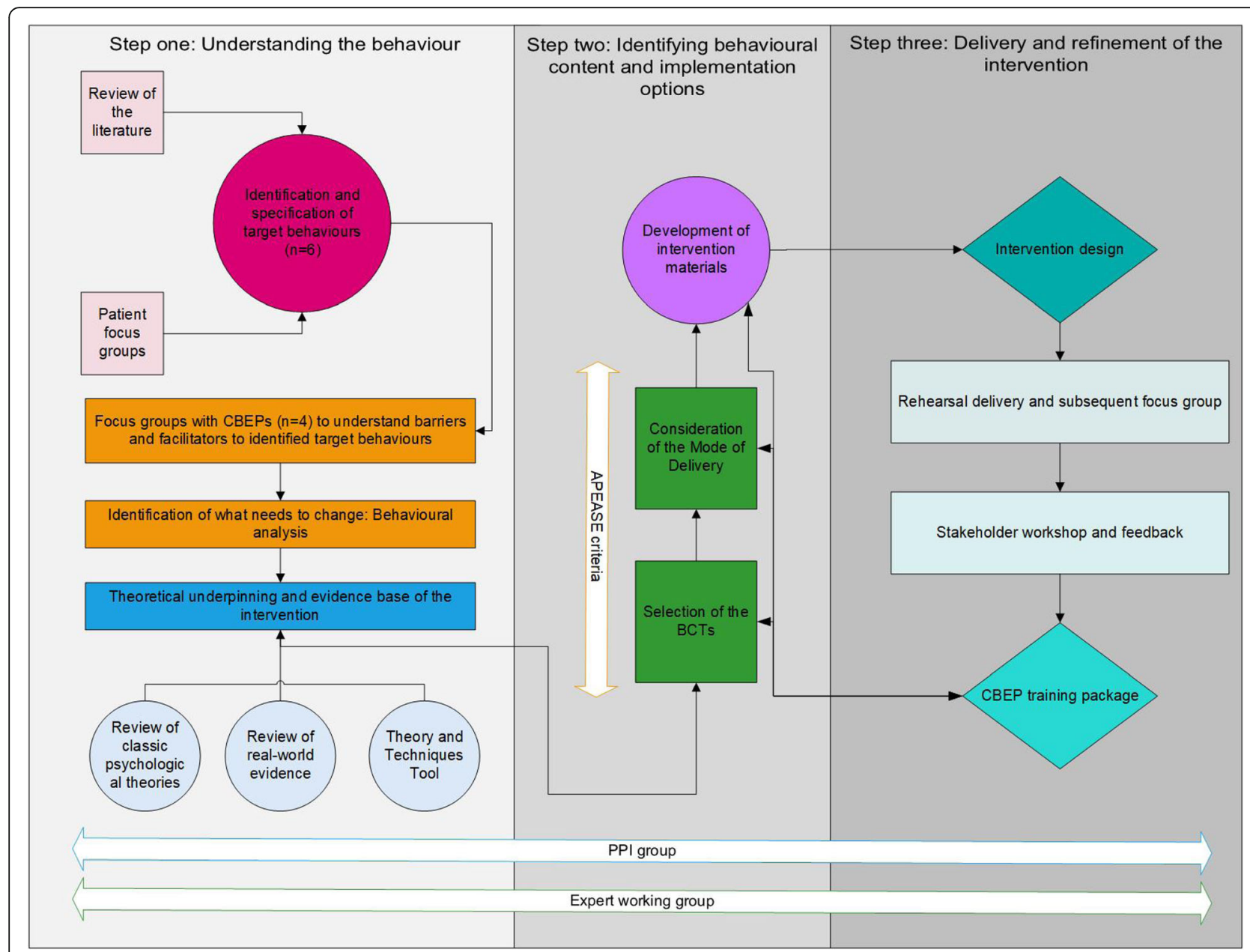

Fig. 1 Iterative intervention development process of a training package for community-based exercise professionals (CBEPS)

\section{Identifying what needs to change}

To further develop our understanding of how CBEPs may support men on ADT to exercise, barriers to, and enablers of the patient target behaviour were identified in the previously reported focus groups [9]. Men were recruited from two urology out-patient departments in South Yorkshire and Derbyshire. All eligible men presenting during routine follow-up care, prostate cancer support groups or via poster advertisement were approached for participation.

Similarly, barriers and facilitators of the CBEPs target behaviours that could be addressed in a training programme were identified from four focus groups. CBEPs were identified from four Nuffield Health fitness and wellbeing gyms using purposive sampling to ensure inclusion of the target population (community-based personal trainers, physiologists, and fitness managers) and relevant stakeholders (gym general managers and operational managers). Study documents were sent via the research team to eligible Nuffield Health employees. Those who provided written consent were enrolled into the study. Each focus group was led by an experienced facilitator (ES, LS, SR) and the topic guide, reviewed by the PPI group, was designed to explore the 14 domains of the Theoretical Domains Framework (TDF) version 2.0 [23] (Additional file 1). The TDF is an integrative framework originally based on the synthesis of 128 theoretical constructs from 33 theories of behaviour change [24] to understand behaviour at an individual level and support the development of implementation interventions [25]. Furthermore, CBEPs were probed on their preferred mode of delivery of the professional training programme (e.g. online versus face-to-face).

Responses from the focus groups were mapped onto the TDF to identify domains through which change may occur. Focus group transcripts were analysed deductively supported by the use of NVivo [26]; the TDF was used to generate the framework for content analysis (SR) and coding specifically identified the type of professional (or patient) who provided the information and the type of professional (or patient) the information was related to (e.g. themselves, a different exercise professional, a HCP 
or patient). The lead researcher (SR) systematically went through each transcript, coding according to the framework. Text was attributed to more than one domain where applicable. Text relating only to the target behaviours were coded for relevance [25]. Subsequently, 25\% of coding was double coded with a second independent reviewer (LS), to develop the coding framework as described above (i.e. who provided the information and the type of professional the information was related to). The coders were in $85 \%$ agreement, and following discussion, all discrepancies were resolved.

\section{Theoretical underpinning and evidence base}

Following the behavioural analysis, psychological theories from the field of behaviour change that related to the identified constructs within the TDF were then reviewed to consider how best to apply them to the current context and advance our understanding of the likely mechanisms of change. In line with MRC guidance for the development and evaluation of complex interventions, a logic model was developed to present the proposed mechanisms of change of the intervention [27].

\section{Step two: identifying behavioural content and implementation options \\ Behaviour change techniques}

Having identified which theoretical constructs required change to achieve both the patient and CBEPs target behaviours, content for the intervention was developed and guided by the inclusion of behaviour change techniques (BCTs). BCTs are defined as observable, replicable, and irreducible components of behaviour change interventions [18]. We used the labels and detailed definitions of BCTs as those included in the BCT Taxonomy version 1 (BCTTv1) [28].

$\mathrm{BCT}$ s to be delivered by the CBEPs to support longterm exercise behaviour were identified from previously drawn links between constructs of the TDF [18], mechanisms of action [29] and previous literature exploring BCTs for promoting exercise behaviour in people living with and beyond cancer [22]. Context-based decisions for each BCT that was identified as likely to be effective (i.e. most frequently used with the selected TDF domains), and supported by evidence, was made in relation to its affordability, practicability, effectiveness and costeffectiveness, acceptability, side effects and safety and equity considerations (APEASE criteria) [18].

Similarly, inclusion of BCTs for the delivery of the exercise professional training were guided by the CBEPs target behaviours and theoretical constructs requiring change. BCTs were identified from previously drawn links between constructs of the TDF [18] and mechanisms of action [29]. BCTs that were identified as effective (i.e. most frequently used with the selected TDF domains) were reviewed against the APEASE criteria and CBEPs focus group findings to determine their suitability in the intervention [18].

\section{Mode of delivery}

Once the BCTs had been identified, the behavioural content was then developed, specifying the mode of delivery. A range of feasible modes of delivering the selected $\mathrm{BCT}$ s were considered and reviewed against the APEA SE criteria [18] to identify content to be delivered via traditional face-to-face approaches and online learning technologies to promote active and self-directed learning [30].

Furthermore, intervention materials including patient booklets and professional training worksheets were created alongside a training manual for CBEPs and a facilitator manual for the training providers.

\section{Step three: delivery and refinement of the intervention} Modelling components of a complex intervention prior to a full-scale study provides important information about the design of the intervention [17]. We sought to operationalise the CBEPs training package during an iterative process, delivering the intervention face-to-face to CBEPs $(n=11)$ and stakeholders $(n=28)$ between February and June 2019, for feedback and refinement of the intervention.

\section{Rehearsal delivery and subsequent focus groups}

The exercise professional training package was delivered to CBEPs who were purposively sampled to ensure a diverse range of target users (e.g. gender, job role and previous experience) [19]. Feedback on the content, format, location and delivery of the intervention were collected immediately post intervention, via an audio recorded focus group with an independent researcher (RT). The topic guide was based on Kirkpatrick's Four Level Training Evaluation Model [31] (Additional file 1) and considers reaction - concerned with understanding how participants feel about the training programme, learning - the extent the attendees have learnt something new such as skills, behaviour - the extent training is put in to practice and results that are obtained as a result of the intervention. Focus group data were analysed in NVivo [26] following Braun and Clarke's six step process of thematic analysis [32]. Suggestions for change were highlighted from the key themes and rated against MoSCoW criteria (Must have, should have, could have, would like) for prioritising change [33]. Modifications were made if they were considered likely to impact on behaviour change, uncontroversial and easy or recommended by multiple participants. 


\section{Stakeholder workshop and feedback}

Following the rehearsal delivery, the exercise professional training package and patient intervention materials were presented at a one-day stakeholder workshop to enhance the future implementation of the designed intervention. Participants were identified via existing clinical, professional and patient networks, national charity representatives and our PPI group. The stakeholder workshop ran in the format of presentations from the research team, presenting 'key uncertainties' for discussion. Stakeholder discussions were facilitated (maximum of 8 per group) by a research team member using a broad topic guide (Additional file 1) based on the Normalisation Process Theory (NPT); a framework that utilises the core concepts of coherence, cognitive participation, collective action and reflexive monitoring to capture the work that participants do when implementing a new practice [34]. Verbal feedback and researcher field notes were collated and circulated to all stakeholders to ask for any further comment or clarification within a two-week deadline. Feedback was then mapped onto the NPT and reviewed against MoSCoW criteria for prioritising change [35], to support intervention refinement, as described above.

\section{Results}

\section{Step one: understanding the behaviour}

Identification, selection and specification of target behaviours

The results of the literature review and focus groups (reported elsewhere [9]) highlighted that most men on ADT are not receiving supervised exercise in line with NICE recommendation (NG131 1.4.19) [8]. Therefore, the target behaviour for men on ADT for prostate cancer was to attend twice weekly supervised exercise sessions, including aerobic and resistance training, for 12 weeks at Nuffield Health. The literature also identified reports of behaviours conducted by exercise professionals in supervising exercise. With the patient target behaviour in mind, these were distilled into 6 unique behaviours that CBEPs should perform. The final list of target behaviours were considered both measurable and modifiable and deemed most likely to bring about change (Table 1).

\section{Identifying what needs to change}

Twenty-six men on ADT participated in one of five focus groups (age range 58-4 years, 96\% White British, $36 \%$ no formal educational qualification, $64 \%$ retired) [9]. Thirty-four barriers to the patient target behaviour were identified, mapping onto 8 domains of the TDF, which highlighted domains requiring targeting (Additional file 2). These were: knowledge, memory, attention and decision processes, beliefs about capabilities, beliefs about consequences, social/ professional role and identity, intention, reinforcement and emotion.

Twenty-two Nuffield Health employed CBEPs participated in one of four focus groups in South Yorkshire, Derbyshire, North Somerset and the West of England (personal trainers $n=11$, physiotherapists $n=$ 4, physiologists $n=3$, fitness managers $n=3$ and general manager $\mathrm{n}=1$ ). Forty-one barriers to the CBEPs target behaviours were identified, that mapped onto 9 domains of the TDF, and thus highlighted domains with required targeting (Additional file 3). These were: knowledge, skill, beliefs about capabilities, beliefs about consequences, social/ professional role and identity, intention, optimism, emotion and environmental context and resources.

Table 1 Specification of target behaviours to focus upon in the STAMINA intervention

\begin{tabular}{|c|c|c|c|}
\hline \multirow[t]{2}{*}{ Target Behaviour } & \multicolumn{3}{|c|}{ Behavioural specifications } \\
\hline & Who & When & Where \\
\hline $\begin{array}{l}\text { 1. To support patients first contact with the } \\
\text { community gym providers }\end{array}$ & $\begin{array}{l}\text { Fitness } \\
\text { manager }\end{array}$ & On receipt of the patient referral & $\begin{array}{l}\text { From the community-based gym, } \\
\text { over the telephone }\end{array}$ \\
\hline 2. To conduct and record results of a fitness test & $\begin{array}{l}\text { Exercise } \\
\text { physiologist }\end{array}$ & At baseline and 12 weeks & At the community-based gym \\
\hline 3. To tailor the exercise prescription & $\begin{array}{l}\text { Exercise } \\
\text { physiologist }\end{array}$ & $\begin{array}{l}\text { At baseline. Weekly reviews to determine } \\
\text { tailoring requirements thereafter. }\end{array}$ & At the community-based gym \\
\hline $\begin{array}{l}\text { 4. To deliver two supervised exercise sessions per } \\
\text { week, per protocol }\end{array}$ & $\begin{array}{l}\text { Personal } \\
\text { trainer }\end{array}$ & Twice a week for 12 weeks & At the community-based gym \\
\hline 5. To provide weekly behavioural support & $\begin{array}{l}\text { Exercise } \\
\text { physiologist } \\
\text { Personal } \\
\text { trainer } \\
\text { Fitness } \\
\text { manager }\end{array}$ & At every contact & $\begin{array}{l}\text { At the community-based gym } \\
\text { and over the phone ad hoc }\end{array}$ \\
\hline $\begin{array}{l}\text { 6. To compile progress reports and communicate } \\
\text { progress with the clinical team }\end{array}$ & $\begin{array}{l}\text { Exercise } \\
\text { physiologist }\end{array}$ & At 12 weeks & At the community-based gym \\
\hline
\end{tabular}


Furthermore, the CBEP focus groups revealed preference for the mode of delivery of the training package to include both face-to-face and online elements.

"I'd much rather we come in and we all sit round and do it. I think with some phys-es like timewise it might be easier if they've got a bit of both. So, if you could have some online too" (Personal Trainer)

\section{Theoretical underpinning of the intervention}

Once the expert working group had identified key domains to target in the intervention, a logic model was developed outlining the assumptions of the intervention based on psychological theories (Fig. 2). The psychological theories that were explored in greater detail were: Social Cognitive theory (SCT: belief in capabilities and skill development) [36], Necessity Concerns Framework (NCF: belief in consequences and knowledge) [36] and Theory of Planned Behaviour (TPB: Professional role/ identity) [37]. Several constructs overlap between these theories e.g. perceived control (TPB) and self-efficacy (SCT), however there are also distinct constructs such as social norms (TPB), focus on skills training (SCT) and decisional balance (NCF) that suggested that whilst the models are complementary there was value in using each of these.

\section{Step two: identify behavioural content and implementation options \\ Behaviour change techniques}

Twenty BCTs were identified to support delivery of the exercise professional training package. Due to the complexity of the intervention, constructs from more than one theory were used to underpin the behavioural content. For example, we included observational learning (i.e. modelling behaviour) with established techniques (i.e. demonstration of behaviour, verbal persuasion) to improve skills and beliefs about capabilities, based on Social Cognitive Theory [36]. To change beliefs about consequences of exercise, and improve knowledge, we provided information about health, social and emotional consequences in line with the Necessity and Concerns framework [38]. Furthermore, the Theory of Planned Behaviour suggests that behaviour is (indirectly) influenced by approval from important others in relation to whether a role should be performed (i.e. subjective norms) and thus we included credible sources to enhance motivation to adhere to the CBEP role [37].

Thirty-one BCTs were also identified to support behaviour change of men on ADT for prostate cancer (Additional file 4). For example, we included action planning, instruction on behaviour and self-reward due to their previous positive association with habit formation and exercise maintenance [39].

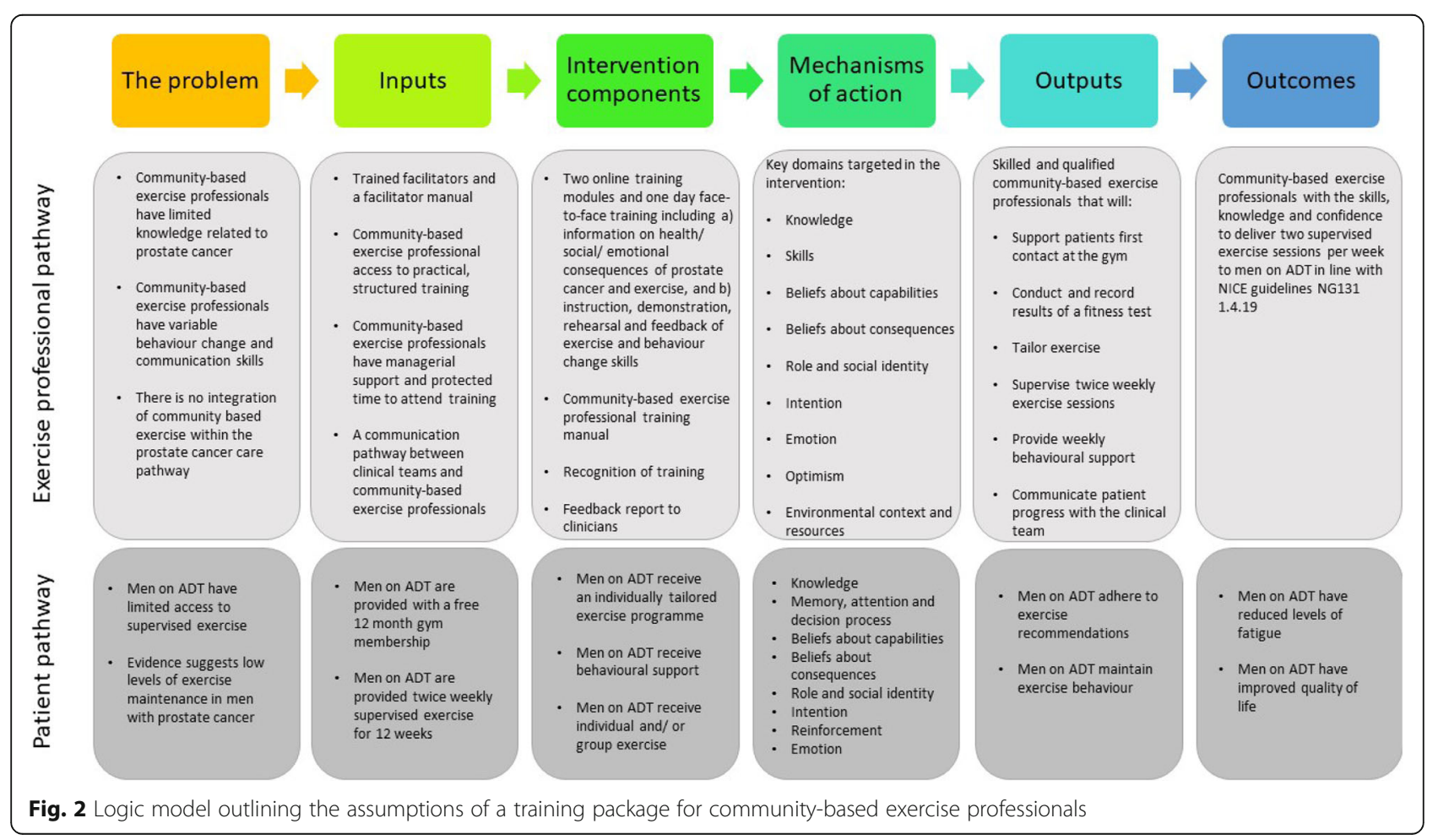




\section{Mode of delivery}

The exercise professional training package was developed to include 8 modules across 2 levels, in line with user preference and principles of blended learning. Level 1 was designed to be delivered individually, online, to provide flexibility for scheduling and completing tasks [40], and included introductory content. The more advanced content and integration of skill based practical learning formed level 2 which was designed to be delivered to groups (minimum 4, maximum 10), face-to-face, in a one-day interactive workshop. An overview of the behavioural content and mode of delivery of both levels is presented in Table 2 .

The BCTs included to support patients exercise behaviour were designed to be delivered face-to-face by CBEPs or presented interactively in a patient journey booklet designed as a behaviour change and self-monitoring tool (Additional file 4).

\section{Step 3: delivery and refinement of the intervention}

The intervention was refined following feedback from CBEPs and stakeholders. A summary of the main changes is provided below, with further detail in Additional file 5.

\section{Rehearsal delivery}

Eleven CBEPs attended the rehearsal training and subsequent focus group. Feedback was categorised into three themes: 1) Content - CBEPs requested contact details to signpost men for further support outside of the exercise professional role (e.g. bone pain or change in medication); 2) Format - CBEPs requested additional time to complete interactive tasks, with a focus on behavioural rehearsal; 3) Recognition - CBEPs enjoyed the training programme but requested accreditation for completion of training as an incentive/ recognition for participation and to enhance trust in the referral pathway. All suggestions were deemed high priority and repeated by several participants thus strategies to implement these changes were made such as providing additional time to facilitate learning and providing CBEPs with a title change on completion of training (i.e. clinical exercise specialist).

\section{Stakeholder workshop}

Feedback from 28 stakeholders (i.e. HCPs, academics, researchers, PPI members, members of local charities, commissioners, senior community-gym staff and CBEPs) was mapped onto the four domains of the NPT (S7): 1) Coherence - it is important to include the evidence-base of STAMINA; 2) Cognitive participation - CBEPs should receive recognition for training completion 3) Collective action - personal trainers possess the skills to fulfil the role of the physiologist and have more time to deliver the intervention; 4) Reflexive monitoring - Level
1 training should be uploaded onto internal systems for ease of access. The feedback, repeated by several participants, mirrored suggestions from CBEPs and were deemed high priority. In response, we provided personal trainers the opportunity to apply for the role of the physiologist, creating an application form with essential and desirable criteria to ensure sufficient skill set ahead of further professional training.

The final intervention is presented in Additional file 6 in line with the Template for Intervention Description and Replication (TIDieR) [41].

\section{Discussion}

This paper describes the methods used and outputs realised from the development and refinement of a theory and evidence-based training package for CBEPs to support the delivery of NICE recommendations (NG131 1.4.19), prior to full effectiveness and implementation evaluation in a planned randomised controlled trial. We demonstrate a systematic approach to intervention development incorporating stakeholder, PPI and user perspectives to optimise safe delivery of a disease specific, tailored exercise programme. Both the process and intervention, if shown to be effective, have the potential to be adapted for exercise interventions with other clinical populations.

To date little is known about the contextual factors that may influence implementation of exercise into the prostate cancer care pathway, in partnership with community gym providers, due to its novelty. In this paper we address this uncertainty by adopting a user-centred design, collecting in-depth qualitative research iteratively, (guided by behavioural theory) to understand user views, context, and experience [19]. This method has similarities to Chaudoir and colleagues' multilevel framework [42], whereby we collected qualitative data from three levels hypothesised to influence implementation outcomes: at the patient, provider and organisational (albeit limited) level [42-44]. Subsequently, we developed an in-depth understanding of patient and professional needs to specify key modifiable behaviours and intervention content that was deemed acceptable, to support behaviour change. More specifically, we designed a training package for CBEPs to address previously reported gaps by incorporating the core competencies of working with clinical populations [16]. A blended learning approach was followed to accommodate different learning styles, and provide opportunity for real-time reflection, questions and discussion [45]. This approach may be advantageous in the current climate whereby social distancing measures are common and digital health/ interventions are rapidly being adopted due to Covid-19 [46]. However, further refinements to the intervention 
Table 2 Overview of the exercise professional training package including summary of content and behaviour change techniques

\begin{tabular}{|c|c|}
\hline $\begin{array}{l}\text { Module } \\
\text { (target behaviour) }\end{array}$ & Summary of content \\
\hline \multicolumn{2}{|l|}{ Level 1: online } \\
\hline $\begin{array}{l}\text { Module 1: } \\
\text { Introduction to } \\
\text { prostate cancer and } \\
\text { exercise (1) }\end{array}$ & $\begin{array}{l}\text { - Provide an overview of the STAMINA programme } \\
\text { and NICE guidelines (text and video from consultant } \\
\text { urologist) } \\
\text { - Provide evidence-base for exercise as a treatment } \\
\text { component (text and video from consultant } \\
\text { urologist) } \\
\text { - Present patient views on exercise (quotes) } \\
\text { - Present information about prostate cancer, } \\
\text { symptoms, mortality, treatment and side effects (text } \\
\text { and video from consultant urologist) } \\
\text { - Present information on the role of CBEPs in STAMINA } \\
\text { (video from consultant urologist) } \\
\text { - Summary of key points }\end{array}$ \\
\hline $\begin{array}{l}\text { Module } 2 \text { : } \\
\text { Operationalising the } \\
\text { STAMINA } \\
\text { programme }(1,4)\end{array}$ & $\begin{array}{l}\text { - Present information on communication with clinical } \\
\text { teams (text and video from consultant urologist) } \\
\text { - Present information on scheduling STAMINA patients } \\
\text { for exercise } \\
\text { - Present frequently asked questions and answers } \\
\text { related to patient memberships, appointments and } \\
\text { missed sessions. }\end{array}$ \\
\hline
\end{tabular}

BCTs (coded in line with BCTTV1)

TDF domain

(target behaviour)

Module 1:

prostate cancer and

urologist)

and video from consultant urologist)

Module 2:

\section{Level 2: Face-to-face}

Module 3: Working - Discussion on prostate cancer treatment, side effects, with clinical populations (1)

5.1 Health consequences, 5.3 Social \&

environmental consequences

4.1 Instruction, 9.1 Credible source

5.6 Emotional consequences, 9.1 Credible source, 10.1 Material incentive

5.1 Health consequences, 5.3 Social \& environmental consequences

4.1 Instruction

4.1 Instruction, 9.1 Credible source

5.6 Emotional consequences, 9.1 Credible source

2.2 Feedback on behaviour, 5.1 Health consequences, 5.3 Social \& environmental consequences symptoms, survival rates and role of exercise.

- Discussion about patient feelings towards attending

the gym and challenge beliefs

- Present detailed information about side effects (case studies)

- Discuss how best to respond to different side effects and consider pros and cons of each

- Provide instruction and demonstration on active listening and helpful phrases to use
4.1 Instruction, 6.1 Demonstration

4.1 Instruction, 9.1 Credible source

9.1 Credible source

5.6 Emotional consequences, 9.1 Credible source, 9.2 Pros and cons, 10.1 Material incentive

5.6 Emotional consequences, 9.1 Credible source, 11.2 Reduce negative emotions

3.2 Social support, 12.5 Adding objects

2.2 Feedback on behaviour, 4.1 Instruction, 5.1 Health consequences, 5.3 Social \& environmental consequences, 5.6 Emotional consequences

2.2 Feedback on behaviour, 4.1 Instruction, 6.1 Demonstration, 8.1 Rehearsal

4.1 Instruction, 15.1 Verbal persuasion

9.1 Credible source, 9.2 Pros and cons

- Information and example of a run-in period provided and discussed

- Practical task with feedback

- Access to case report forms and instruction on how to access NHS.net

Module 5: Delivering the exercise prescription (4)
- Discussion about consequences of monitoring exercise and previous experience, focussing on success

- Discussion about challenges of delivering to small groups and persuasion of capability

- Instruction and demonstration of recording heart rate and exertion

- Practical graded task delivering and recording tailored exercise to small groups, with feedback
3.3 Social support, 11.2 Reduce negative emotions

12.5 Adding objects

2.2 Feedback on behaviour, 4.1 Instruction, 8.1 Rehearsal, 8.7 Graded task

2.2 Feedback on behaviour, 4.1 Instruction, 8.1 Rehearsal, 8.7 Graded task, 15.1 Verbal persuasion, 15.3 Focus on past success

5.1 Health consequences, 5.3 Social \& environmental consequences, 5.6 Emotional consequences, 9.1 Credible source, 10.1 Material
Knowledge

Professional

role

Beliefs about consequences

Knowledge

Skill

Professional role

Beliefs about consequences

Knowledge

Skill

Professional

role

Intention

Beliefs about consequences

Emotion

Environmental context

Knowledge

Skill

Professional

role

Beliefs about consequences

Emotion

Environmental context

Skill

Beliefs about capabilities

Beliefs about consequences 
Table 2 Overview of the exercise professional training package including summary of content and behaviour change techniques (Continued)

\begin{tabular}{|c|c|c|c|}
\hline $\begin{array}{l}\text { Module } \\
\text { (target behaviour) }\end{array}$ & Summary of content & BCTs (coded in line with BCTTV1) & TDF domain \\
\hline & - Information that protected time to deliver exercise & incentive, 10.8 Incentive & \\
\hline & & 3.3 Social support, 11.2 Reduce negative emotions & Emotion \\
\hline & & $\begin{array}{l}3.2 \text { Social support, } 12.1 \text { Restructure, } 12.5 \text { Adding } \\
\text { objects }\end{array}$ & $\begin{array}{l}\text { Environmental } \\
\text { context }\end{array}$ \\
\hline \multirow{5}{*}{$\begin{array}{l}\text { Module 6: } \\
\text { Reviewing the } \\
\text { exercise prescription } \\
\text { (6) }\end{array}$} & \multirow{5}{*}{$\begin{array}{l}\text { - Discuss importance of reviewing exercise } \\
\text { - Provide instruction on professional role } \\
\text { - Provide instruction and demonstration of } \\
\text { completing a progress report (case study) } \\
\text { - Role play task: completing progress reports and } \\
\text { discussing progress. Feedback provided. } \\
\text { - Discuss importance of language used } \\
\text { - Verbal persuasion about capabilities and focus on } \\
\text { past success }\end{array}$} & $\begin{array}{l}\text { 2.2 Feedback on behaviour, } 4.1 \text { Instruction, } 6.1 \\
\text { Demonstration, } 8.1 \text { Rehearsal }\end{array}$ & Skill \\
\hline & & 4.1 Instruction & $\begin{array}{l}\text { Professional } \\
\text { role }\end{array}$ \\
\hline & & 15.1 Verbal persuasion & Optimism \\
\hline & & $\begin{array}{l}\text { 3.3 Social support, } 11.2 \text { Reduce negative emotions, } \\
15.1 \text { Verbal persuasion }\end{array}$ & Emotion \\
\hline & & 12.5 Adding objects & $\begin{array}{l}\text { Environmental } \\
\text { context }\end{array}$ \\
\hline \multirow[t]{5}{*}{$\begin{array}{l}\text { Module 7: Behaviour } \\
\text { change (5) }\end{array}$} & \multirow{5}{*}{$\begin{array}{l}\text { - Discuss what behaviour is, how it is influenced and } \\
\text { how it can be changed, focus on past success } \\
\text { - Introduce behaviour change theory } \\
\text { - Discuss capability, opportunity and motivation of } \\
\text { men on ADT and challenge beliefs (case study } \\
\text { videos) } \\
\text { - Present patient video discussing the importance of } \\
\text { the exercise professional role and behavioural } \\
\text { support } \\
\text { - Role play task: respond to exercise ambivalence/ } \\
\text { resistance (case studies). } \\
\text { - Review task in group discussion and provide } \\
\text { feedback. } \\
\text { - Provide instruction/ demonstration of suitable BCTs } \\
\text { for exercise ambivalence and resistance } \\
\text { - Role play task: repeated with new skills learnt } \\
\text { - Discussion and video examples of good and bad } \\
\text { communication focusing on the spirit of } \\
\text { motivational interviewing }\end{array}$} & $\begin{array}{l}\text { 2.2 Feedback on behaviour, } 4.1 \text { Instruction, } 5.6 \\
\text { Emotional consequences }\end{array}$ & Knowledge \\
\hline & & $\begin{array}{l}\text { 1.2 Problem solving, 2.2 Feedback on behaviour, } \\
\text { 4.1 Instruction, } 6.1 \text { Demonstration, } 8.1 \text { Rehearsal, } \\
\text { 8.7 Graded task }\end{array}$ & Skill \\
\hline & & 4.1 Instruction & $\begin{array}{l}\text { Professional } \\
\text { role }\end{array}$ \\
\hline & & $\begin{array}{l}\text { 2.2 Feedback on behaviour, } 4.1 \text { Instruction, } 6.1 \\
\text { Demonstration, } 8.1 \text { Rehearsal, } 8.7 \text { Graded task, } 15.1 \\
\text { Verbal persuasion, } 15.3 \text { Focus on past success }\end{array}$ & $\begin{array}{l}\text { Beliefs about } \\
\text { capabilities }\end{array}$ \\
\hline & & $\begin{array}{l}\text { 5.1 Health consequences, } 5.6 \text { Emotional } \\
\text { consequences, } 9.1 \text { Credible source }\end{array}$ & $\begin{array}{l}\text { Beliefs about } \\
\text { consequences }\end{array}$ \\
\hline \multirow[t]{6}{*}{$\begin{array}{l}\text { Module 7: Fitness } \\
\text { Testing (2) }\end{array}$} & \multirow{6}{*}{$\begin{array}{l}\text { - Introduce the fitness test and provide handouts } \\
\text { (protocol, exertion scale, case report form) } \\
\text { - Provide instruction and demonstration on the gym } \\
\text { floor } \\
\text { - Discuss safe parameters of exercise testing (case } \\
\text { study) } \\
\text { - Access to gym floor and heart rate monitors for } \\
\text { practical, graded task with feedback using case } \\
\text { report forms to record outcomes (i.e. heart rate, } \\
\text { exertion, time, level) }\end{array}$} & $\begin{array}{l}\text { 2.2 Feedback on behaviour, } 4.1 \text { Instruction, } 5.1 \\
\text { Health consequences }\end{array}$ & Knowledge \\
\hline & & $\begin{array}{l}\text { 2.2 Feedback on behaviour, } 4.1 \text { Instruction, } 6.1 \\
\text { Demonstration, } 8.1 \text { Rehearsal, } 8.7 \text { Graded task }\end{array}$ & Skill \\
\hline & & 4.1 Instruction & $\begin{array}{l}\text { Professional } \\
\text { role }\end{array}$ \\
\hline & & 5.6 Emotional consequences, 9.1 Credible source & $\begin{array}{l}\text { Beliefs about } \\
\text { consequences }\end{array}$ \\
\hline & & 11.2 Reduce negative emotions & Emotion \\
\hline & & 12.1 Restructure environment, 12.5 Adding objects & $\begin{array}{l}\text { Environmental } \\
\text { context }\end{array}$ \\
\hline
\end{tabular}

may be required if remote delivery extends to clinical exercise services for people with cancer.

Feedback from intervention users and stakeholders highlighted modifications which could further improve intervention effectiveness and implementation into the real-world. For example, integration of an exercise referral pathway between two currently distinct sectors (i.e. the NHS and leisure industry) may benefit from formal recognition/ accreditation of professional training to reduce previously reported concerns regarding CBEPs skills to deliver a safe, and disease specific exercise programme [9]. Furthermore, uploading online training content to the university as opposed to the organisation's website was perceived as a potential barrier, which if addressed, could further optimise implementation. These observations will require confirmation in our planned definitive randomised controlled trial whereby treatment fidelity will be measured, i.e. professional's application and delivery of the skills learnt in training into real-life context [47] and a qualitative process evaluation 
conducted to identify areas that may require further refinement [27].

\section{Implications for implementation and future work}

To date, exercise is the only evidence-based treatment to help manage side effects of ADT [6,7]. However, exercise is rarely offered as standard treatment for prostate cancer [9] and many barriers to implementation exist when delivered by exercise professionals working in health services, including: pathway inadequacy, limited scope for scalability and limited skillset, i.e. delivered to a more limited range of clinical populations than efficacy studies and clinical guidelines indicate would be beneficial. We demonstrate a potential solution - the development of a referral pathway between two currently distinct sectors, which, when combined with professional training ( $\mathrm{HCP}$ and $\mathrm{CBEP}$ ) as part of a complex intervention, can support the delivery of NICE recommendations nationally. The next steps are to test the effectiveness and cost-effectiveness of the intervention in a definitive randomised trial. We will also conduct a process evaluation focussing on implementation outcomes such as how well the intervention is adopted in services and if it is seen as acceptable and appropriate by stakeholders, CBEPs and patients. In this sense the trial can be considered to adhere to a type 1 hybrid design [48] which is increasingly recommended for trials of this sort.

We also emphasise the importance of combining formalised intervention development approaches to ensure the approach is systematic, user centred, theory and evidence based and conducted at multilevel to enhance implementation. This approach allows for interventions to be refined and adapted to reach larger target audiences, i.e. to support other clinical populations where exercise is beneficial but under-utilised.

\section{Strengths and limitations}

The methods reported in this paper were based on a combination of formalised intervention development approaches $[18,19]$, to address limitations of each approach. For example, the $\mathrm{BCW}$ provides a systematic process to intervention development and is presented as a simple stepwise process to enhance usability. However, optimal intervention development takes a much more lengthy, non-linear process [49] and thus we took an iterative approach to intervention development as suggested by the MRC guidance for the development of complex interventions [17]. We also included components of the PBA to gain ongoing feedback from user perspectives to optimise future implementation. Furthermore, we addressed previously reported barriers to integrating NICE recommendations into practice $[10,11]$, by developing an intervention to be delivered by community providers; to enhance patient accessibility and scalability during the implementation process [50]. Furthermore, NHS services are currently under extreme pressure due to the coronavirus pandemic [51] thus highlighting the need to explore new pathways of care.

A common limitation of intervention development approaches is the limited guidance, or evidence to support the selection of BCTs in clusters, and the unclear instructions on how to select and apply appropriate theories to support intervention content. For example, most theories predict behaviour as opposed to providing clear instructions and techniques on how to change behaviour [52]. However, the Social Cognitive Theory [36] is an exception as it provides examples of techniques to influence behaviour change. To further improve the generalisability of our methods we took a triangulation approach reviewing evidence-based links [29] and most frequently used BCTs [18] against pre-defined criteria (i.e. APEASE) and ensured consensus was achieved amongst our expert working group.

\section{Conclusion}

This paper describes the development and refinement of a training package to support CBEPs implementing NICE recommendations into prostate cancer care. We demonstrate how established intervention development approaches can be combined to provide a systematic approach to developing a theory and evidence-based intervention and emphasise the importance of incorporating stakeholder, PPI and user perspective to ensure the intervention remains relevant and acceptable to the recipient during each refinement iteration. Both the process and intervention have the potential to be adapted for exercise interventions with other clinical populations where exercise is recommended but underutilised.

\section{Abbreviations}

APEASE: Affordability, Practicability, Effectiveness and Cost-effectiveness, Acceptability, Side effects and Safety, Equity considerations; ADT: Androgen Deprivation Therapy; BCTs: Behaviour Change Techniques; BCW: Behaviour Change Wheel; CBEP: Community-based exercise professional;

HCP: Healthcare professional; MoSCoW: Must have, Should have, Could have, Would like; MRC: Medical Research Council; NICE: The National Institute for Health and Care Excellence; NPT: Normalisation Process Theory; PPI: Patient and Public Involvement; QoL: Quality of Life; STAMINA: Supported exercise TrAining for Men wlth prostate caNcer on Androgen deprivation therapy; TDF: Theoretical Domains Framework; TIDieR: Template for Intervention Description and Replication; UK: United Kingdom

\section{Supplementary Information}

The online version contains supplementary material available at https://doi. org/10.1186/s12913-021-06275-w.

Additional file 1. Topic guides. This file contains three topic guides that were used for primary qualitative data collection in the intervention development and refinement process 1) Focus groups pre-rehearsal delivery to community-based exercise professionals, 2) Focus groups post- 
rehearsal delivery to community-based exercise professionals and 3) Round table discussion during the stakeholder workshop.

Additional file 2. Barriers to exercising twice weekly as reported by men on androgen deprivation therapy for prostate cancer: mapped onto the Theoretical Domains Framework. This file contains a list of barriers and example quotes to exercising twice weekly in a gym, reported by men on androgen deprivation therapy for prostate cancer. Responses are mapped onto the Theoretical Domains Framework.

Additional file 3. Barriers to supervising exercising twice weekly as reported by community-based exercise professionals: mapped onto the Theoretical Domains Framework. This file contains a list of barriers and example quotes to supervising men on androgen deprivation therapy for prostate cancer to exercise twice weekly in a gym, reported by community-based exercise professionals. Responses are mapped onto the Theoretical Domains Framework.

Additional file 4. Summary of the patient intervention. This file provides a summary of the behavioural content of the patient intervention.

Additional file 5. Intervention refinements based on feedback from community-based exercise professionals and stakeholders. This file provides feedback on the intervention (training package) following rehearsal delivery to community-based exercise professionals and presentation to stakeholders. Feedback is collated into key themes. Where modifications were made, criteria for change and a description of the impact upon the intervention is provided.

Additional file 6. Template for Intervention Description and Replication (TIDieR) of the community-based exercise professional intervention. This file provides an overview of the community-based exercise professional intervention (training package).

\section{Acknowledgements}

To participants, the PPI group, Nuffield Health and STAMINA co-applicants. The STAMINA co-applicants include Tom Baker, Michelle Collinson, Professor Patrick Doherty, Professor Amanda Farrin, Professor Diana Greenfield*, Suzanne Hartley, Professor Jenny Hewison, Professor Malcom Mason and Dr. David Meads.

*Diana Greenfield is a National Institute for Health Research (NIHR) Senior Nurse Research Leader. The views expressed in this article are those of the author and not necessarily those of the NIHR, or the Department of Health and Social Care.

\section{Authors' contributions}

Conceptualization: DJR, LB, LS, ST; Methodology: SR, RT, LS, ES; Formal Analysis: SR and LS; Writing-Original Draft Preparation: SR; Writing-Review \& Editing: SR, RT, LS, ST, LB, DM, JB, ES, DJR; Funding Acquisition, DJR and LB. The authors read and approved the final manuscript.

\section{Funding}

This work was supported by the National Institute of Health Research [grant number RP-PG-1016-20007].

\section{Availability of data and materials}

The datasets supporting the conclusions of this article are included within the article (and its additional files).

\section{Declarations}

Ethics approval and consent to participate

Ethical approvals for research activities were sought from Sheffield Hallam University (Reference: ER10748795) and the NHS (REC reference: 18/NW/0738 / IRAS project ID: 254343).

\section{Consent for publication}

NA.

\section{Competing interests}

The authors declare one competing interest. Professor Janet Brown reports: personal fees from Novartis, Amgen, BMS, Ipsen, MSD, Daiichi-Sankyo, Sandoz, Bayer and institutional grants from Amgen, Bayer, outside the submitted work.

\section{Author details}

${ }^{1}$ Allied Health Professionals, Radiotherapy and Oncology, Sheffield Hallam University, Sheffield, UK. ${ }^{2}$ Population Health Sciences, University of Bristol, Bristol, UK. ${ }^{3}$ Institute for Population Health Sciences, Queen Mary University of London, London, UK. ${ }^{4}$ Sports and Exercise Medicine, William Harvey Research Institute, School of Medicine and Dentistry, Queen Mary University of London, London, UK. ${ }^{5}$ Department of Oncology and Metabolism, University of Sheffield, Sheffield, UK. ${ }^{6}$ Department of Urology, Sheffield Teaching Hospitals, Sheffield, UK.

Received: 15 December 2020 Accepted: 11 March 2021

Published online: 22 March 2021

\section{References}

1. Ferlay J, Colombet M, Soerjomataram I, Mathers C, Parkin DM, Piñeros $\mathrm{M}$, et al. Estimating the global cancer incidence and mortality in 2018: GLOBOCAN sources and methods. Int J Cancer. 2019;144:1941-53 WileyLiss Inc.

2. Cancer registration statistics, England - Office for National Statistics. [cited 2020 May 22]. Available from: https://www.ons.gov.uk/peoplepopulationa ndcommunity/healthandsocialcare/conditionsanddiseases/bulletins/ca ncerregistrationstatisticsengland/2017. Accessed 19 Nov 202.

3. Sharifi N, Gulley JL, Dahut WL. Androgen deprivation therapy for prostate cancer. J Am Med Assoc. 2005;294:238-44 American Medical Association; [cited 2020 Oct 1]. Available from: https://jamanetwork.com/.

4. Stein KD, Syrjala KL, Andrykowski MA. Physical and psychological long-term and late effects of cancer. Cancer 2008;112(S11):2577-2592. [cited 2020 May 22]. Available from: https://doi.org/10.1002/cncr.23448

5. Ahmadi H, Daneshmand S. Androgen deprivation therapy: evidence-based management of side effects. BJU Int 2013;111(4):543-548. [cited 2020 May 6]. Available from: https://doi.org/10.1111/j.1464-410X.2012.11774.x

6. Bourke L, Smith D, Steed L, Hooper R, Carter A, Catto J, et al. Exercise for men with prostate cancer: A systematic review and meta-analysis. Eur Urol. 2016;69:693-703 Elsevier B.V.

7. Nguyen PL, Alibhai SMH, Basaria S, D'Amico AV, Kantoff PW, Keating NL, et al. Adverse effects of androgen deprivation therapy and strategies to mitigate them. Eur Urol. 2015;67:825-36 Elsevier.

8. Recommendations. Prostate cancer: diagnosis and management; Guidance: NICE; 2019. [cited 2020 Apr 28]. Available from: https://www. nice.org.uk/guidance/ng131/chapter/recommendations\#people-havinghormone-therapy

9. Bourke L, Turner R, Greasley R, Sutton E, Steed L, Smith D, et al. A multicentre investigation of delivering national guidelines on exercise training for men with advanced prostate cancer undergoing androgen deprivation therapy in the UK NHS. PLoS One 2018;13(7):e0197606. [cited 2020 Apr 24]. Jiang B-H, editor. Available from: https://doi.org/10.1371/journal.pone.01 97606

10. Cantwell M, Walsh D, Furlong B, Moyna N, McCaffrey N, Boran L, et al. Healthcare professionals' knowledge and practice of physical activity promotion in cancer care: Challenges and solutions. Eur I Cancer Care 2018; 27(2):e12795. [cited 2020 Oct 1]. Available from: https://doi.org/10.1111/ ecc. 12795

11. Roberts AL, Potts HWW, Stevens C, Lally P, Smith L, Fisher A. Cancer specialist nurses' perspectives of physical activity promotion and the potential role of physical activity apps in cancer care. J Cancer Surviv. 2019; 13(5):815-28 [cited 2021 Feb 19]. Available from: https://pubmed.ncbi.nlm. nih.gov/31475306/.

12. King AJL, Evans M, Moore THM, Paterson C, Sharp D, Persad R, et al. Prostate cancer and supportive care: a systematic review and qualitative synthesis of men's experiences and unmet needs. Eur J Cancer Care 2015;24(5):618-634. [cited 2020 Oct 1]. Available from: https://doi.org/10.1111/ecc.12286

13. Bourke L, Stevenson R, Turner R, Hooper R, Sasieni P, Greasley R, et al. Exercise training as a novel primary treatment for localised prostate cancer: A multi-site randomised controlled phase II study. Sci Rep. 2018;8(1):8374 [cited 2020 Sep 18]. Available from: https://pubmed.ncbi.nlm.nih.gov/2984 9032/.

14. Bourke L, Gilbert S, Hooper R, Steed LA, Joshi M, Catto JWF, Saxton JM, Rosario DJ. Lifestyle changes for improving disease-specific quality of life in sedentary men on long-term androgen-deprivation therapy for advanced prostate cancer: a randomised controlled trial. Eur Urol. 2014;65(5):865-72. https://doi.org/10.1016/j.eururo.2013.09.040. 
15. Chartered status [cited 2020 Oct 1]. Available from: https://www.cimspa.co. uk/chartered-status. Accessed 19 Nov 2020.

16. Warburton DER, Bredin SSD, Charlesworth SA, Foulds HJA, McKenzie DC, Shephard RJ. Evidence-based risk recommendations for best practices in the training of qualified exercise professionals working with clinical populations. Appl Physiol Nutr Metabol. 2011;36:232-65 NRC Research Press.

17. O'Cathain A, Croot L, Duncan E, Rousseau N, Sworn K, Turner KM, et al. Guidance on how to develop complex interventions to improve health and healthcare. BMJ Open. 2019;9(8):e029954. https://doi.org/10.1136/bmjopen-2 019-029954.

18. Michie $S$, Atkins $L$, West $R$. The behaviour change wheel : a guide to designing interventions; 2014. p. 329.

19. Yardley L, Morrison L, Bradbury K, Muller I. The person-based approach to intervention development: application to digital health-related behavior change interventions. J Med Internet Res. 2015;17(1):e30 [cited 2020 Apr 22]. Available from: http://www.ncbi.nlm.nih.gov/pubmed/25639757.

20. Band R, Bradbury K, Morton K, May C, Michie S, Mair FS, et al. Intervention planning for a digital intervention for self-management of hypertension: a theory-, evidence- and person-based approach. Implement Sci. 2017;12(1):113.

21. Craig P, Dieppe P, Macintyre S, Mitchie S, Nazareth I, Petticrew M. Developing and evaluating complex interventions: The new Medical Research Council guidance. BMJ. 2008;337:979-83 British Medical Journal Publishing Group.

22. Turner RR, Steed L, Quirk H, Greasley RU, Saxton JM, Taylor SJC, et al. Interventions for promoting habitual exercise in people living with and beyond cancer. Cochrane Database of Systematic Reviews. 2018;19: CD010192 John Wiley and Sons Ltd.

23. Cane J, O'Connor D, Michie S. Validation of the theoretical domains framework for use in behaviour change and implementation research. Implement Sci. 2012;7(1):1-17.

24. Michie S, Johnston M, Abraham C, Lawton R, Parker D, Walker A. Making psychological theory useful for implementing evidence based practice: a consensus approach. Quality and Safety in Health Care: BMJ Publishing Group Ltd; 2005. p. 26-33.

25. Atkins L, Francis J, Islam R, O'connor D, Patey A, Ivers N, et al. A guide to using the Theoretical Domains Framework of behaviour change to investigate implementation problems. Implement Sci. 2017;12:1-8 [cited 2020 Apr 22]; Available from: http://www.implementationscience.com/series/TDF.

26. QSR International Pty Ltd. NVivo (Version 11). 2015 [cited 2011 Aug 20]. Available from: https://www.qsrinternational.com/nvivo-qualitative-data-ana lysis-software/home

27. Moore GF, Audrey S, Barker M, Bond L, Bonell C, Hardeman W, et al. Process evaluation of complex interventions: Medical Research Council guidance. BMJ. 2015;350 [cited 2020 Oct 9]; Available from: http://www.bmj.com/.

28. Michie S, Richardson M, Johnston M, Abraham C, Francis J, Hardeman W, et al. The behavior change technique taxonomy ( $v 1$ ) of 93 hierarchically clustered techniques: Building an international consensus for the reporting of behavior change interventions. Ann Behav Med. 2013;46(1):81-95 [cited 2020 Oct 9]. Available from: https://pubmed.ncbi.nlm.nih.gov/23512568/.

29. Welcome / Theory and Techniques Tool [cited 2020 Apr 27]. Available from: https://theoryandtechniquetool.humanbehaviourchange.org/. Accessed 19 Nov 2020.

30. Williams C. Learning On-line: A review of recent literature in a rapidly expanding field. J Further Higher Educ. 2002;26:263-72 Taylor \& Francis Group.

31. Kirkpatrick DL. Evaluating training programs: evidence vs. proof. Train Dev J. 1977:9-12 [cited 2020 Oct 9]. Available from: https://agris.fao.org/agris-sea rch/search.do?recordID=US201302470542.

32. Braun V, Clarke V. Using thematic analysis in psychology. Qual Res Psychol 2006:3(2):77-101. [cited 2018 Jun 25]. Available from: https://doi.org/10.11 91/1478088706qp063oa

33. Bradbury K, Morton K, Band R, van Woezik A, Grist R, McManus RJ, et al. Using the person-based approach to optimise a digital intervention for the management of hypertension. PLoS One. 2018;13(5):e0196868.

34. Murray E, Treweek S, Pope C, MacFarlane A, Ballini L, Dowrick C, et al. Normalisation process theory: A framework for developing, evaluating and implementing complex interventions. BMC Med 2010;8(1):1-11. [cited 2020 Jul 7]. Available from: https://doi.org/10.1186/1741-7015-8-63

35. Kuhn J. Decrypting the MoSCoW Analysis. 2009 [cited 2020 Jul 7]. Available from: http://www.itsmsolutions.com/newsletters/DITYvol5iss44.htm
36. Bandura A. Social foundations of thought and action: A social cognitive theory Prentice-Hall: Prentica-Hall; 1986. p. 617. [cited 2020 Jul 15]. Available from: https://books.google.co.uk/books?id=HJhqAAAAMAAJ

37. Ajzen I. From Intentions to Actions: A Theory of Planned Behavior. In: Action Control. Heidelberg: Springer Berlin; 1985. p. 11-39.

38. Phillips LA, Diefenbach MA, Kronish IM, Negron RM, Horowitz CR. The necessity-concerns framework: a multidimensional theory benefits from multidimensional analysis. Ann Behav Med. 2014;48(1):7-16 [cited 2020 Aug 21]. Available from: https://academic.oup.com/abm/article/48/1/7-16/4564 051.

39. Howlett N, Trivedi D, ... NT-T behavioral, 2019 undefined. Are physical activity interventions for healthy inactive adults effective in promoting behavior change and maintenance, and which behavior change techniques are. academic.oup.com [cited 2020 May 22]; Available from: https://aca demic.oup.com/tbm/article-abstract/9/1/147/4913688. Accessed 19 Nov 2020

40. Rovai AP. A constructivist approach to online college learning. Internet High Educ. 2004;7(2):79-93. https://doi.org/10.1016/j.iheduc.2003.10.002.

41. Template for Intervention Description and Replication (TIDieR) | Cochrane Training. [cited 2020 Oct 9]. Available from: https://training.cochrane.org/ resource/template-intervention-description-and-replication-tidier. Accessed 19 Nov 2020.

42. Chaudoir SR, Dugan AG, Barr CH. Measuring factors affecting implementation of health innovations: A systematic review of structural, organizational, provider, patient, and innovation level measures. Implement Sci 2013;8(1):1-20. [cited 2020 Jul 15]. Available from: https://doi.org/10.11 86/1748-5908-8-22

43. Durlak JA, DuPre EP. Implementation matters: A review of research on the influence of implementation on program outcomes and the factors affecting implementation. Am J Community Psychol 2008;41(3-4):327-350. [cited 2020 Jul 15]. Available from: https://doi.org/10.1007/s10464-008-9165-0

44. Damschroder LJ, Aron DC, Keith RE, Kirsh SR, Alexander JA, Lowery JC. Fostering implementation of health services research findings into practice: A consolidated framework for advancing implementation science. Implement Sci 2009;4(1):50. [cited 2020 Jul 15]. Available from: https://doi. org/10.1186/1748-5908-4-50

45. Eagleton S. Designing blended learning interventions for the 21st century student. Adv Physiol Educ 2017;41(2):203-211. [cited 2020 May 22]. Available from: https://doi.org/10.1152/advan.00149.2016

46. Keesara S, Jonas A, Schulman K. Covid-19 and Health Care's Digital Revolution. N Engl J Med 2020;382(23):e82. [cited 2020 Nov 11]. Available from: https://doi.org/10.1056/NEJMp2005835

47. Borrelli B. The assessment, monitoring, and enhancement of treatment fidelity in public health clinical trials. J Public Health Dent 2011;71(SUPPL. 1): S52-S63. [cited 2020 Jul 15]. Available from: https://doi.org/10.1111/j.17527325.2011.00233.x

48. Curran GM, Bauer M, Mittman B, Pyne JM, Stetler C. Effectivenessimplementation hybrid designs: Combining elements of clinical effectiveness and implementation research to enhance public health impact. Med Care. 2012;50(3):217-26 [cited 2021 Feb 25]. Available from: https://pubmed.ncbi.nlm.nih.gov/22310560/.

49. Sinnott C, Mercer SW, Payne RA, Duerden M, Bradley CP, Byrne M. Improving medication management in multimorbidity: development of the MultimorbiditY COllaborative medication review and DEcision making (MY COMRADE) intervention using the behaviour change wheel. Implement Sci. 2015;10(1):1-11.

50. Aarons GA, Sklar M, Mustanski B, Benbow N, Brown CH. "Scaling-out" evidence-based interventions to new populations or new health care delivery systems. Implement Sci. 2017;12(1) [cited 2021 Feb 2]. Available from: https://pubmed.ncbi.nlm.nih.gov/28877746/.

51. Propper C, Stoye G, Zaranko B. The Wider Impacts of the Coronavirus Pandemic on the NHS *. Fisc Stud 2020;41(2):345-356. [cited 2021 Feb 25]. Available from: https://doi.org/10.1111/1475-5890.12227

52. De Silva MJ, Breuer E, Lee L, Asher L, Chowdhary N, Lund C, et al. Theory of Change: A theory-driven approach to enhance the Medical Research Council's framework for complex interventions. Trials 2014;15(1):1-13. [cited 2020 Nov 11]. Available from: https://doi.org/10.1186/1745-6215-15-267

\section{Publisher's Note}

Springer Nature remains neutral with regard to jurisdictional claims in published maps and institutional affiliations. 